\title{
Efficiency of different quadrat sizes and shapes for sampling standing crop
}

\author{
JOE E. BRUMMER, JAMES T. NICHOLS, RUSSELL K. ENGEL, AND KENT M. \\ ESKRIDGE
}

\begin{abstract}
Authors are range research coordinator, professor of agronomy, and research technologist, University of Nebraska, West Central Res. and Ext. Center, North Platte 69101; and assistant professor of biometry, University of Nebraska, Lincoln 68583.
\end{abstract}

\begin{abstract}
Efficient sampling of standing crop is necessary to avoid unreasonable outlays of time in the field. The objective of this study was to determine efficiency of different size and shape quadrats for sampling standing crop of total herbage and individual species. Three blocks $1.2 \times 12 \mathrm{~m}$ were divided into 160 basic units using 30 $\times 30-\mathrm{cm}$ quadrats. Basic units were combined into 18 size/shape combinations of quadrats. Current year standing crop was clipped in each basic unit into categories of sand bluestem (Andropogon hallii Hack.), prairie sandreed [Calamovilfa longifolia (Hook.) Scribn.], hairy grama (Bouteloua hirsuta Lag.), little bluestem [Schizachyrium scoparium (Michx.) Nash], and other herbage. Variance was used to determine sample number necessary to accurately and precisely estimate standing crop. Sample number was then used in conjunction with movement time between quadrats and clipping time to determine total field time as a measure of overall efficiency. Increasing quadrat size accounted for $68 \%$ or more of the observed decrease in variance. Long, narrow rectangles were more efficient for reducing variances of prairie sandreed and hairy grama, but shape had little effect on variances of sand bluestem, little bluestem, and total herbage. Groups of quadrats were similar in total field time with no "best" quadrat identified for any of the vegetation categories. Larger quadrats than those reported in the literature were found to be more efficient as a result of including movement time in the optimization procedures. Large amounts of total field time were required to efficiently estimate standing crop of little bluestem, which may require that alternative sampling methods be devised or used to estimate standing crop of this species and others with similar distribution patterns.
\end{abstract}

Key Words: sampling unit, Andropogon hallü Hack., Calamovilfa longifolia (Hook.) Scribn., Bouteloua hirsuta Lag., Schizachyrium scoparium (Michx.) Nash, Nebraska Sandhills

Standing crop estimates are necessary on rangeland to set stocking rates, determine changes in range condition, and evaluate vegetation responses to treatments (Pieper 1978). Accurate and precise estimates are difficult to obtain because of the large number of species with different distribution patterns and production potentials, which results in large sample variances (Thompson 1958, Greig-Smith 1964). Size, shape, and number of quadrats used to sample a population have been shown to affect sample variance (Pechanec and Stewart 1940, Wiegert 1962, Van Dyne et al. 1963, Wight 1967, Papanastasis 1977). Quadrats that minimize variance are statistically more efficient.

The number of samples needed to obtain accurate and precise estimates is determined by the variance of a quadrat. A large

Published as Paper 10157, Journal Serics, Nebraska Agr. Res. Div.

Manuscript accepted 26 Jun. 1993 number of quadrats must generally be sampled, regardless of size or shape, to estimate standing crop of individual species with high levels of accuracy and precision (Pechanec and Stewart 1940, Van Dyne et al. 1963, Wight 1967, Mueggler 1976). Relative to individual species, fewer quadrats are needed for accurate and precise estimates of total herbage or broad categories such as grasses, forbs, or shrubs (Van Dyne et al. 1963, Mueggler 1976).

Time or cost efficiency must be considered in conjunction with statistical efficiency when evaluating quadrats of different sizes and shapes. Small quadrats have large variances but require less clipping time. When both time and statistical efficiencies were considered for quadrats of various sizes, small quadrats were determined to be "optimum" (Wiegert 1962, Van Dyne et al. 1963, Papanastasis 1977). However, these authors did not consider that large numbers of small quadrats are necessary to efficiently estimate standing crop relative to larger quadrats. Movement time between quadrats must also be considered with clipping time in order to make valid comparisons among quadrats of different sizes and shapes.

The objective of this study was to determine efficiency of different size and shape quadrats for sampling standing crop of total herbage and individual species. Variance was used to calculate number of samples needed to accurately and precisely estimate standing crop. Number of samples was then used in conjunction with movement time between quadrats and clipping time to determine total field time as a measure of efficiency.

\section{Materials and Methods}

Research was conducted at the University of Nebraska Gudmundsen Sandhills Laboratory located $11 \mathrm{~km}$ northeast of Whitman, Neb. Soils are Valentine fine sands (mixed, mesic Typic Ustipsamments) derived from eolian sand parent material. Vegetation is dominated by mid and tall grasses including little bluestem [Schizchyrium scoparium (Michx.) Nash], sand bluestem (Andropogon hallii Hack.), and prairie sandreed [Calamovilfa longifolia (Hook.) Scribn.]. Other common species are hairy grama (Bouteloua hirsuta Lag.), sand dropseed [Sporobolus cryptandrus (Torr.) Gray], prairie junegrass [Koeleria pyramidata (Lam.) Beauv.], switchgrass (Panicum virgatum L.), western ragweed (Ambrosia psilostachya DC.), and sedges (Carex spp.).

Three sampling areas $(1.2 \times 12.0 \mathrm{~m})$ were randomly located on ungrazed sands range sites in July 1988. Each area was divided into 160 basic units using $30 \times 30-\mathrm{cm}$ quadrats. Current year standing crop was clipped at ground level in each basic unit and separated into categories of little bluestem, sand bluestem, prairie sandreed, hairy grama, and other herbage. Samples were dried at $60^{\circ} \mathrm{C}$ for 72 hours and weighed. The 5 categories were summed to determine total herbage. Contiguous basic units were combined to deter- 
Table 1. Quadrats evaluated with corresponding shape, area, and sample number per block.

\begin{tabular}{lccc}
\hline \hline $\begin{array}{l}\text { Quadrat } \\
\text { dimensions }\end{array}$ & $\begin{array}{c}\text { Quadrat } \\
\text { shape }^{1}\end{array}$ & $\begin{array}{c}\text { Quadrat } \\
\text { area }\end{array}$ & $\begin{array}{c}\text { Sample } \\
\text { no. }\end{array}$ \\
\hline$(\mathrm{m})$ & & $\left(\mathrm{m}^{2}\right)$ & \\
$0.3 \times 0.3$ & Square & 0.09 & 160 \\
$0.3 \times 0.6$ & 2X Rect. & 0.18 & 80 \\
$0.3 \times 1.2$ & 4X Rect. & 0.36 & 40 \\
$0.3 \times 1.5$ & 5X Rect. & 0.45 & 32 \\
$0.3 \times 2.4$ & 8X Rect. & 0.72 & 20 \\
$0.3 \times 3.0$ & 10X Rect. & 0.90 & 16 \\
$0.3 \times 6.0$ & 20X Rect. & 1.80 & 8 \\
$0.3 \times 12.0$ & 40X Rect. & 3.60 & 4 \\
$0.6 \times 0.6$ & Square & 0.36 & 40 \\
$0.6 \times 1.2$ & 2X Rect. & 0.72 & 20 \\
$0.6 \times 1.5$ & 2.5X Rect. & 0.90 & 16 \\
$0.6 \times 2.4$ & 4X Rect. & 1.44 & 10 \\
$0.6 \times 3.0$ & 5X Rect. & 1.80 & 8 \\
$0.6 \times 6.0$ & 10X Rect. & 3.60 & 4 \\
$1.2 \times 1.2$ & Square & 1.44 & 10 \\
$1.2 \times 1.5$ & 1.25X Rect. & 1.80 & 8 \\
$1.2 \times 2.4$ & 2X Rect. & 2.88 & 5 \\
$1.2 \times 3.0$ & 2.5X rect. & 3.60 & 4 \\
\hline
\end{tabular}

iShape of rectangles was determined by the ratio of length to width.

mine standing crop for 18 size/shape combinations of quadrats (Table 1). Only size/shape combinations which used all 160 basic units from a sampling area were investigated.

Experimental design was a randomized complete block with the 3 areas designated as blocks. Sample variances were calculated by block for each quadrat. Variance estimates were transformed prior to analysis of variance using a rank procedure to correct for the nonnormal distribution of variances (Conover and Iman 1981). Quadrat shapes were compared within a given quadrat size using single degree of freedom contrasts since size and shape were confounded due to the study design. Regression was used to evaluate variance change in relation to quadrat size as proposed by Smith (1938).

Sample number was determined for each quadrat by block using the formula: $n=z^{2} s^{2} / d^{2}$, where $n=$ sample number, $z=$ table $z$-value, $s^{2}=$ variance of each quadrat, and $d=$ one-half the acceptable yield level (Steel and Torrie 1980). Sample number was calculated for total herbage and each of 4 individual species to obtain standing crop estimates within $10 \%$ of the mean with $95 \%$ confidence.

Movement time among quadrats and actual clipping time were determined using square quadrats $0.09,0.36,0.81$, and $1.44 \mathrm{~m}^{2}$. Three observers randomly located 20 sample points each by pacing $X: Y$ coordinates in a 1.8-ha ungrazed pasture. At each point, all 4 quadrat sizes were hand clipped for sand bluestem, prairie sandreed, hairy grama, little bluestem, or total herbage. Clipping time included separating plant material along quadrat borders and separating previous years' dead herbage from current year herbage. The relationship between quadrat size and clipping time for each species and total herbage was determined by linear regression. Regression coefficients (slopes) were compared among species and total herbage by analysis of covariance (Steel and Torrie 1980). Single degree of freedom contrasts were used to compare: (1) total herbage to all species, (2) rhizomatous (sand bluestem) to rhizomatous (prairie sandreed), (3) bunchgrass (hairy grama) to bunchgrass (little bluestem), and (4) rhizomatous to bunchgrass species.

Total field time for each quadrat was calculated by multiplying both movement and clipping time by sample number required to estimate standing crop within $10 \%$ of the mean with $95 \%$ confidence. Normality of the time data was tested followed by analysis of variance to compare total field time among the 18 quadrats.
Time data for little bluestem and total herbage had nonnormal distributions which were corrected by using logarithmic transformations. The quadrat that required the least amount of total field time when averaged over blocks was considered the "best" for each vegetation category. A mean separation procedure described by Lentner and Bishop (1986) was used to compare the "best" quadrat to all others.

\section{Results and Discussion}

\section{Standing Crop}

A rigorous evaluation of variation within a block was possible because standing crop estimates were the same for all quadrat size/shape combinations within each block (Table 2). Standing

Table 2. Standing crop of total herbage, sand bluestem (ANHA), prairie sandreed (CALO), hairy grama (BOHI), little bluestem (SCSC), and other herbage for the 3 blocks.

\begin{tabular}{|c|c|c|c|c|}
\hline \multirow[b]{2}{*}{ Category } & \multicolumn{3}{|c|}{ Block } & \multirow[b]{2}{*}{ Average } \\
\hline & 1 & 2 & 3 & \\
\hline & \multicolumn{4}{|c|}{ 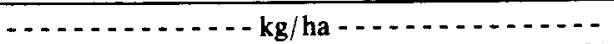 } \\
\hline Total & 1026 & 897 & 1080 & $1001 \pm 541$ \\
\hline ANHA & 169 & 123 & 205 & $166 \pm 24$ \\
\hline CALO & 133 & 99 & 208 & $147 \pm 32$ \\
\hline $\mathrm{BOHI}$ & 142 & 140 & 128 & $137 \pm 4$ \\
\hline SCSC & 143 & 286 & 312 & $247 \pm 53$ \\
\hline Other & 439 & 247 & 227 & $304 \pm 68$ \\
\hline
\end{tabular}

iStandard error of the mean.

crop was the same because all quadrats were constructed using a combination of all 160 basic units from a block. Variation among locations (or blocks) should be considered in conjunction with variation within a location because vegetation patterns differ both within and among locations. Coefficient of variation for standing crop among blocks was $38 \%$ for prairie sandreed, little bluestem, and other herbage, $25 \%$ for sand bluestem, $9 \%$ for total herbage, and $5 \%$ for hairy grama. Although the same vegetation type was sampled, diversity among locations was present which impacted variance estimates (i.e., statistical efficiency) for the different quadrats.

\section{Variance}

Variance estimates for total and individual species standing crop decreased with increasing quad rat size (Table 3 ) with $68 \%$ or more of the decrease explained by the increase in quadrat size (Table 4). Regression coefficients ranged from -0.82 for sand bluestem to -0.97 for little bluestem (Table 4). Smith (1938) used the regression coefficient as a measure of soil and plant heterogeneity. He stated that values near -1 indicated heterogeneous distribution of standing crop and little correlation among quadrats that were adjacent to one another. For values near -1 , as with little bluestem, doubling quadrat size reduced variance by about one-half. The closer the regression coefficient was to 0 , the less efficient it was statistically to use larger quadrat sizes. The advantage of using smaller quadrat sizes was greater for the other species and total herbage, as far as statistical efficiency was concerned, since their regression coefficients were greater than -1 .

The effect of quadrat shape on variance estimates varied by vegetation category (Table 5). Quadrat shape had no effect on variance estimates for little bluestem and no consistent effect for sand bluestem and total herbage. Quadrat size accounted for $94 \%$ or more of the observed decrease in variance for these 3 vegetation categories (Table 4). If quadrat shape affects variance estimates, it is generally rectangular shapes that are more efficient (Soplin et al. 1975, Wight 1967, Risser 1984). Rectangular quadrats intersect more vegetation patches than square quadrats thereby maximizing 
Table 3. Variance sample number, and total area needed to obtain standing crop estimates for total herbage, sand bluestem (ANHA), prairie sandreed (CALO), hairy grama (BOHI), and little bluestem (SCSC) for quadrats of various sizes and shapes. Sample number and total area required were calculated for estimates to be within $10 \%$ of the mean with $95 \%$ confidence.

\begin{tabular}{|c|c|c|c|c|c|c|c|c|c|c|c|c|c|c|c|c|}
\hline \multirow[b]{2}{*}{ Shapel } & \multirow[b]{2}{*}{ Size } & \multicolumn{5}{|c|}{ Variance } & \multicolumn{5}{|c|}{ Number } & \multicolumn{5}{|c|}{ Area } \\
\hline & & Total & ANHA & CALO & BOHI & SCSC & Total & ANHA & CALO & BOHI & SCSC & Total & ANHA & CALO & BOHI & SCSC \\
\hline & $\left(\mathrm{m}^{2}\right)$ & & & & & & & & & & & & & $\left(m^{2}\right)-$ & $\ldots$ & $\ldots$ \\
\hline $1 \times 1$ & 0.09 & 247415 & 17707 & 22283 & 17265 & 275795 & 95 & 247 & 396 & 353 & 1737 & 9 & 22 & 36 & 32 & 156 \\
\hline $1 \times 2$ & 0.18 & 135300 & 11735 & 15965 & 10792 & 159122 & 52 & 164 & 284 & 221 & 1002 & 9 & 29 & 51 & 40 & 180 \\
\hline $1 \times 4$ & 0.36 & 68939 & 7273 & 8779 & 6118 & 77873 & 26 & 101 & 156 & 125 & 490 & 10 & 37 & 56 & 45 & 177 \\
\hline $2 \times 2$ & 0.36 & 93120 & 7521 & 10970 & 8298 & 109675 & 36 & 105 & 195 & 170 & 691 & 13 & 38 & 70 & 61 & 249 \\
\hline $1 \times 5$ & 0.45 & 52082 & 5683 & 6861 & 5016 & 64847 & 20 & 79 & 122 & 103 & 408 & 9 & 36 & 55 & 46 & 184 \\
\hline $1 \times 8$ & 0.72 & 46573 & 4395 & 5216 & 3496 & 52169 & 18 & 61 & 93 & 72 & 328 & 13 & 44 & 67 & 52 & 237 \\
\hline $2 \times 4$ & 0.72 & 46003 & 4988 & 6797 & 4890 & 53256 & 18 & 70 & 121 & 100 & 335 & 13 & 50 & 87 & 72 & 241 \\
\hline $1 \times 10$ & 0.90 & 30150 & 3207 & 3670 & 2452 & 31704 & 12 & 45 & 65 & 50 & 200 & 10 & 40 & 59 & 45 & 180 \\
\hline $2 \times 5$ & 0.90 & 35075 & 3524 & 5329 & 4196 & 42762 & 13 & 49 & 95 & 86 & 269 & 12 & 44 & 85 & 77 & 242 \\
\hline $2 \times 8$ & 1.44 & 33592 & 2792 & 4393 & 2980 & 36738 & 13 & 39 & 78 & 61 & 231 & 19 & 56 & 112 & 88 & 333 \\
\hline $4 \times 4$ & 1.44 & 18025 & 2848 & 5620 & 3054 & 21387 & 7 & 40 & 100 & 63 & 135 & 10 & 57 & 144 & 90 & 194 \\
\hline $1 \times 20$ & 1.80 & 21301 & 1348 & 821 & 878 & 17359 & 8 & 19 & 15 & 18 & 109 & 15 & 34 & 26 & 32 & 197 \\
\hline $2 \times 10$ & 1.80 & 20127 & 1708 & 2855 & 2077 & 17832 & 8 & 24 & 51 & 43 & 112 & 14 & 43 & 91 & 77 & 202 \\
\hline $4 \times 5$ & 1.80 & 12602 & 2239 & 4397 & 2377 & 17504 & 5 & 31 & 78 & 49 & 110 & 9 & 56 & 141 & 88 & 198 \\
\hline $4 \times 8$ & 2.88 & 12273 & 1885 & 4082 & 1770 & 14003 & 5 & 26 & 73 & 36 & 88 & 14 & 76 & 209 & 104 & 254 \\
\hline $1 \times 40$ & 3.60 & 9979 & 598 & 324 & 548 & 9300 & 4 & 8 & 6 & 11 & 59 & 14 & 30 & 21 & 40 & 211 \\
\hline $2 \times 20$ & 3.60 & 13508 & 963 & 589 & 642 & 9114 & 5 & 13 & 10 & 13 & 57 & 19 & 48 & 38 & 47 & 207 \\
\hline $4 \times 10$ & 3.60 & 11254 & 1069 & 2586 & 1056 & 5529 & 4 & 15 & 46 & 22 & 35 & 16 & 54 & 165 & 78 & 125 \\
\hline
\end{tabular}

'Quadrat shape is expressed in dimensions of number of basic units $(1$ basic unit $=30 \times 30 \mathrm{~cm})$

Table 4. Regression relationships of log variance versus log quadrat size $\left(m^{2}\right)$ for estimates of total herbage, sand bluestem, (ANHA), prairie sandreed (CALO), hairy grama (BOHI), and little bluestem (SCSC) standing crop.

\begin{tabular}{lccc}
\hline \hline Category & Intercept ${ }^{1}$ & $\begin{array}{l}\text { Regression } \\
\text { coefficient }\end{array}$ & $\mathrm{r}^{2}$ \\
\hline Total & 4.502 & -0.846 & 0.96 \\
ANHA & 3.485 & -0.821 & 0.94 \\
CALO & 3.598 & -0.850 & 0.68 \\
BOHI & 3.454 & -0.838 & 0.88 \\
SCSC & 4.512 & -0.971 & 0.96 \\
\hline
\end{tabular}

'Regression relationship follows Smith (1938).

Table 5. Probabilities of single degree of freedom contrasts used to compare variance estimates of quadrat shapes within given quadrat sizes for total herbage, sand bluestem (ANHA), prairie sandreed (CALO), hairy grama (BOHI), and little bluestem (SCSC).

\begin{tabular}{lccccc}
\hline \hline Contrast & Total & ANHA & CALO & BOHI & SCSC \\
\hline $4 X$ vs Square $\left(0.36 \mathrm{~m}^{2}\right)$ & NS & NS & NS & NS & NS \\
$8 X$ vs $2 X\left(0.72 \mathrm{~m}^{2}\right)$ & NS & NS & 0.03 & 0.02 & NS \\
$10 X$ vs $2.5 X\left(0.90 \mathrm{~m}^{2}\right)$ & NS & NS & 0.01 & $<0.01$ & NS \\
$4 X$ vs Square $\left(1.44 \mathrm{~m}^{2}\right)$ & $<0.01$ & NS & 0.02 & NS & NS \\
$20 X$ vs $5 X\left(1.80 \mathrm{~m}^{2}\right)$ & NS & NS & NS & 0.01 & NS \\
$20 X \& 5 X$ vs $1.25 X$ & 0.01 & 0.09 & $<0.01$ & $<0.01$ & NS \\
$\quad\left(1.80 \mathrm{~m}^{2}\right)$ & & & & & \\
$40 X$ vs $10 \times\left(3.60 \mathrm{~m}^{2}\right)$ & NS & NS & NS & NS & NS \\
$40 X \& 10 X$ vs $2.5 X$ & NS & NS & 0.08 & 0.03 & NS \\
$\left(3.60 \mathrm{~m}^{2}\right)$ & & & & & \\
\hline
\end{tabular}

'Non-significant $(P>0.10)$.

within quadrat variation which reduces between quadrat variation. Quadrat shape only affected variance estimates for total herbage within 2 quadrat sizes, but it is worthwhile to note that the square or nearly square quadrats had lower variance estimates than the long, narrow rectangular quadrats in both comparisons. Square quadrats can be more efficient than rectangles when the size of the square is about the size of the vegetation patches (Risser 1984). The $1.2 \times 1.2$ and $1.2 \times 1.5-\mathrm{m}$ quadrats were about the same size and may have approximated the size of the vegetation patches (i.e., distribution of total herbage). Van Dyne et al. (1963) found that circular quadrats had lower variances compared to rectangular quadrats of the same size for sampling standing crop of Montana bunchgrass range. Their findings were also in contrast to the general concept that rectangular quadrats are more efficient.

Rectangular quadrats generally reduced variances of standing crop estimates for prairie sandreed and hairy grama (Table 5). Five of the 8 contrasts were significant for each species, all of which favored the use of rectangles over squares or rectangles with higher length to width ratios compared to smaller ratios. The influence of increasing quadrat size on variance reduction was lowest for these 2 species (Table 4), which supports the larger influence of quadrat shape. Variance reduction due to quadrat shape ranged from 23 to $82 \%$ and 29 to $58 \%$ for prairie sandreed and hairy grama, respectively.

\section{Number and Area}

Quadrat size and shape directly affected sample variance, which in turn determined sample number and total clipped area needed to obtain standing crop estimates within desired accuracy and precision levels (Table 3). Even though variances were large for total herbage, sample numbers required to efficiently estimate standing crop were small compared to the individual species. For most quadrats tested, at least 3 times more samples were required to estimate standing crop of individual species than total herbage. Sand bluestem required the least samples for a given quadrat followed by hairy grama, prairie sandreed, and little bluestem. Large sample numbers were required to efficiently sample standing crop of little bluestem regardless of quadrat size or shape. Variance estimates for identical quadrats were about equal for total herbage and little bluestem, but little bluestem required about 17 times more samples than total to achieve the same levels of accuracy and precision. Large differences in standing crop estimates between little bluestem and total herbage caused this difference in required sample numbers.

The total area to be clipped was a function of sample number and quadrat size (Table 3 ). The smallest quadrat required the largest sample number for the desired estimate, but the total area to be clipped for both total herbage and individual species was close 
to the smallest. Standing crop estimates of total herbage required the smallest total sampling area of the 5 vegetation categories for any given quadrat. Averaged over all quadrats, sand bluestem, hairy grama, prairie sandreed, and little bluestem required 3.6,5.1, 6.9, and 17.1 times more total sampling area, respectively, than total herbage to achieve the same levels of accuracy and precision. The amount of sampling area required to estimate standing crop of little bluestem may be prohibitive and require that accuracy and / or precision levels be lowered to avoid an unreasonable outlay of time and labor.

\section{Time}

Movement time averaged about 2 min between sample points and accounted for over $50 \%$ of total field time when large sample numbers were required (Fig. 1). Averaged across all quadrats, movement time constituted $11,38,36,23$, and $23 \%$ of total field time for total herbage, sand bluetem, prairie sandreed, hairy grama, and little bluestem, respectively. A larger percentage of total time was spent moving when a particular species was easy to clip. For example, sand bluestem and prairie sandreed occurred as single stems which did not contain dead herbage that required separation from current year herbage. Their growth form and lack of dead herbage allowed most stems in a quadrat to be handled as one handful, which lowered clipping time.

Clipping time increased lincarly $\left(r^{2} \geq 0.93\right)$ as quadrat size increased for all categories of vegetation (Table 6). The rate of

Table 6. Linear regression relationships of clipping time $(\mathrm{min})$ versus quadrat size ( $\mathrm{m}^{2}$ ) for estimates of total herbage, sand bluestem (ANHA), prairie sandreed (CALO), hairy grama (BOHI), and little bluestem (SCSC) standing crop.

\begin{tabular}{lccc}
\hline \hline Category & Intercept & $\begin{array}{l}\text { Regression } \\
\text { coefficient }\end{array}$ & $\mathrm{r}^{2}$ \\
\hline Total & 2.369 & 18.92 & 0.97 \\
ANHA & 0.370 & 3.24 & 0.94 \\
CALO & 0.536 & 3.31 & 0.99 \\
BOHI & 1.065 & 6.80 & 0.96 \\
SCSC & 2.190 & 4.70 & 0.93 \\
\hline
\end{tabular}

increase in clipping time per unit area was higher $(P<0.01)$ for total herbage when contrasted to the other species. The rate of increase in clipping time was similar $(P>0.10)$ between the 2 rhizomatous species, sand bluestem and prairie sandreed, or between the 2 bunchgrass species, hairy grama and little bluestem. However, clipping time increased at a higher $(P=0.08)$ rate for the bunchgrasses in contrast to the rhizomatous species. Total current year herbage in a quadrat, amount of dead herbage associated with a particular species, and the morphology of the different species all affected clipping time. Hairy grama was particularly time consuming to clip because of its short growth form, need for separation of previous years' dead herbage, and difficulty in locating it among the associated taller species. Within a quadrat size, clipping time for total herbage was 2.7 to 6.0 times greater than clipping time for any individual species. Clipping hairy grama and little bluestem required the most time for a given quadrat size. Therefore, clipping time for total herbage increased as these 2 species became more abundant.

Total field time (movement plus clipping) to sample within $10 \%$ of the mean with $95 \%$ confidence varied among quadrats within a vegetation category (Fig. 1). There were considerable differences in field time among some vegetation categories for given quadrats. Little bluestem required the greatest amount of total time to adequately sample. Van Dyne et al. (1963) found that aggregated clusters of large bunchgrass clumps caused abnormally high varia- tion in standing crop from quadrat to quadrat which indicated that different species or groups of species required different shapes, sizes, and numbers of quadrats for equally efficient estimates.

The $0.3 \times 12 \mathrm{~m}\left(3.60 \mathrm{~m}^{2}\right)$ quadrat required the least total field time for both sand bluestem and prairie sandreed (Fig. 1). The 0.3 $\times 6 \mathrm{~m}\left(1.80 \mathrm{~m}^{2}\right), 1.2 \times 3 \mathrm{~m}\left(3.60 \mathrm{~m}^{2}\right)$, and $1.2 \times 1.5 \mathrm{~m}\left(1.80 \mathrm{~m}^{2}\right)$ quadrats were lowest in total field time for hairy grama, little bluestem, and total herbage, respectively. Although these quadrats were "best", on average, for a specific vegetation category, groups of quadrats were similar $(P>0.10)$ in total field time to the "best" because of large variability among the 3 blocks (Fig. 1). The vegetation pattern within a block influenced how a given quadrat encompassed the variation which in turn affected estimates of total field time. For example, the quadrat that required the least total field time to sample for little bluestem ranked 1, 2, and 11 in the different blocks. Without prior testing in a specific sampling situation, any one of the quadrats in the group could be just as efficient at reducing field time. Studies of quadrat size and shape reported in the literature have generally used some method or criteria to choose one "best" quadrat for the vegetation of interest (Wassom and Kalton 1953, Wiegert 1962, Van Dyne et al. 1963, Soplin et al. 1975, and Papanastasis 1977). Results from our study indicated that it was unlikely one "optimum" quadrat could be used in "all" sampling situations, even within the same vegetation type. The 3 blocks sampled in this study were on the same range site. Even so, the large variability encountered among blocks resulted in a group of quadrats that was not different from the "best". Results from most previous studies must interpreted within the context in which the data were collected since variability among blocks or locations was not used in determining "optimum" quadrats. Pearce et al. (1988) stated that no one "optimum" quadrat size and shape exists for a particular crop under all circumstances.

Another important point brought out by the optimization procedure used in our study was that the "best" quadrat and those grouped with it were larger in size than most other "optimum" quadrats reported in the literature. Van Dyne et al. (1963) concluded that a $0.18 \mathrm{~m}^{2}$ circular quadrat and a $0.3 \times 1.21 \mathrm{~m}\left(0.36 \mathrm{~m}^{2}\right)$ rectangular quadrat were most efficient for estimating total herbage of 2 bunchgrass ranges in Montana based on minimizing variance and clipping time. Using similar optimization procedures, Wiegert (1962) concluded that the "optimum" quadrat size for sampling standing crop of forbs and total green herbage was 0.187 $\mathrm{m}^{2}$, for grass $0.047 \mathrm{~m}^{2}$, and for dead herbage $0.063 \mathrm{~m}^{2}$ on an old field in Michigan. Papanastasis (1977) found that a $0.0625 \mathrm{~m}^{2}$ quadrat was "optimum" for sampling total herbage of bunchgrass ranges in Greece. Using an optimization procedure proposed by Smith (1938), Soplin et al. (1975) concluded that a $0.04-\mathrm{m}^{2}$ quadrat was "optimum" for sampling standing crop of coastal bermudagrass [Cynodon dactylon (L.) Pers.]. Small quadrats are more efficient statistically, but require larger sample numbers to get reliable estimates of standing crop. An important factor not considered by most authors in their calculation of cost was movement time between quadrats. When movement time is considered, as it was in our study, the "optimum" quadrat becomes larger because small quadrats require large sample numbers which increases movement time relative to clipping time (Fig. 1). Movement time averaged $2 \mathrm{~min}$ between quadrats on a 1.8-ha sampling area in our study. Increases in the size of the sampling area would increase movement time between quadrats. Movement time would then make up a larger proportion of total field time and cause the "optimum" quadrat size to become even larger than those reported in this study. Movement and clipping time are both important factors in the field collection of standing crop estimates and should be considered in optimization procedures in the future. Consideration of only clipping time appears to have led some authors to 

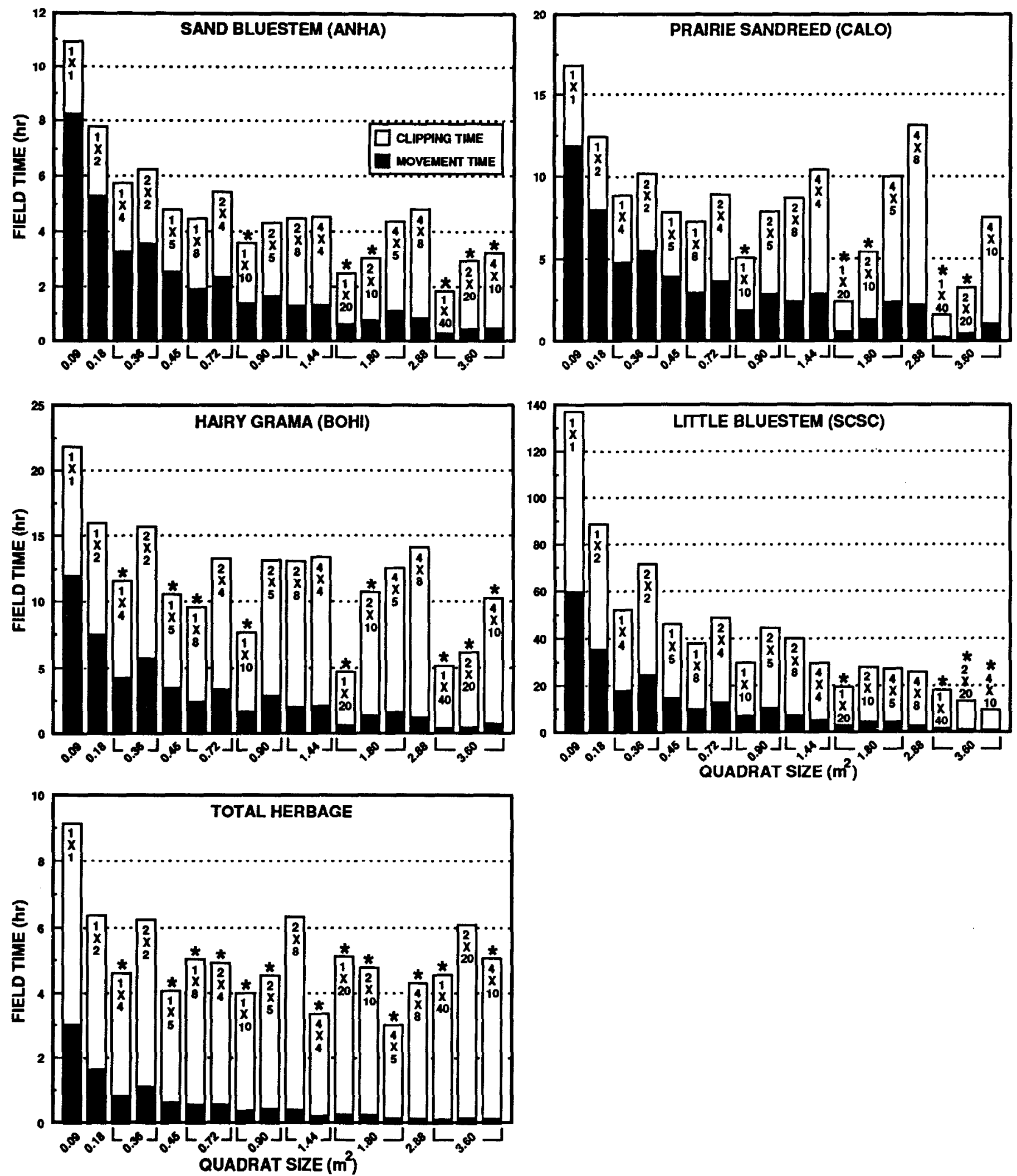

Fig. 1. Total field time required to estimate standing crop of total herbage, sand bluestem (ANHA), prairie sandreed (CALO), hairy grama (BOHI), and little bluestem (SCSC) for 18 quadrats. Each bar represents the time required to move between and clip the number of quadrats necessary to be within $10 \%$ of the mean with $95 \%$ confidence. Quadrats not different $(P>0.10)$ from the "best" are indicated with a *above the bar. 
recommend smaller quadrats than are probably "optimum".

\section{Conclusions}

Increasing quadrat size accounted for $68 \%$ or more of the observed decrease in variance. The effect of quadrat shape on reducing variance was inconsistent among the vegetation categories. Long, narrow rectangular quadrats were more efficient for reducing variance estimates of prairie sandreed and hairy grama, but quadrat shape had little effect on variance estimates for sand bluestem, little bluestem, and total herbage.

Efficiency of individual quadrats was not consistent because the vegetation pattern varied among locations. Instead, groups of "best" quadrats were similar in total field time required to accurately and precisely estimate standing crop. This finding was in contrast to other studies in the literature that reported only 1 "optimum" quadrat.

The inclusion of movement time between quadrats along with clipping time in optimization procedures was considered essential to better evaluate total time required to collect standing crop estimates in the field. Larger quadrats than those reported in the literature were found to be "best" as a result of including movement time in the optimization procedures.

Large amounts of total field time were required to reliably estimate standing crop of little bluestem. Desired accuracy and/ or precision levels may need to be lowered or alternative sampling methods devised or used to estimate standing crop of little bluestem and species with similar distribution patterns.

\section{Literature Cited}

Conover, W.J., and R.L. Iman. 1981. Rank transformations as a bridge between parametric and nonparametric statistics. The Amer. Statistician 35:124-129.

Greig-Smith, P. 1964. Quantitative plant ecology. Butterworth Sci. Publ., London, England.
Lentner, M., and T. Bishop. 1986. Experimental design and analysis. Valley Book Co., Blacksburg, Va.

Mueggler, W.F. 1976. Number of plots required for measuring productivity on mountain grasslands in Montana. USDA Forest Serv. Res. Note INT-207 (Revised).

Papanastasis, V.P. 1977. Optimum size and shape of quadrat for sampling herbage weight in grasslands of northern Greece. J. Range Manage. 30:446-448.

Pearce, S.C., G.M. Clarke, G.V. Dyke, and R.E. Kempson. 1988. A manual of crop experimentation. Oxford Univ. Press, N.Y.

Pechanec, J.F., and G. Stewart. 1940. Sagebrush-grass range sampling studies: size and structure of sampling unit. J. Amer. Soc. Agron. 32:669-682.

Pieper, R.D. 1978. Measurement techniques for herbaceous and shrubby vegetation. New Mexico State Univ.

Risser, P.G. 1984. Methods for inventory and monitoring of vegetation, litter, and soil surface condition. In: Developing strategies for rangeland management. Westview Press, Boulder, Colo.

Smith, H.F. 1938. An empirical law describing heterogeneity in the yields of agriculture crops. J. Agr. Sci. 28:1-23.

Soplin, H., H.D. Gross, and J.O. Rawlings. 1975. Optimum size of sampling unit to estimate coastal bermadgrass yield. Agron. J. 67:533-537.

Steel, R.G.D. and J.H. Torrie. 1980. Principles and procedures of statistics. McGraw-Hill Book Co., N.Y.

Thompson, H.R. 1958. The statistical study of plant distribution patterns using a grid of quadrats. Aust. J. Bot. 6:322-342.

Van Dyne, G.M., W.G. Vogel, and H.G. Fisser. 1963. Influence of small plot size and shape on range herbage production estimates. Ecology 44:746-759.

Wassom, C.E., and R.R. Kalton. 1953. Estimations of optimum plot size using data from bromegrass uniformity trials. Iowa Agr. Exp. Sta. Bull. 396.

Wiegert, R.G. 1962. The selection of an optimum quadrat size for sampling the standing crop of grasses and forbs. Ecology 43:125-129.

Wight, J.R. 1967. The sampling unit and its effect on saltbush yield estimates. J. Range Manage. 20:323-325. 